\title{
Elasticidades de Armington para o Brasil: 1986-2002*
}

\section{Octávio Augusto Fontes Tourinho ${ }^{\dagger}$, Honorio Kume ${ }^{\ddagger}$, Ana Cristina de Souza Pedroso ${ }^{\S}$}

Sumário: 1. Introdução; 2. A Elasticidade de Armington e a Abertura Comercial no Brasil; 3. Análise Empírica; 4. Resultados; 5. Conclusões; A. Fonte e Tratamento dos Dados; B. Determinação da Ordem de Integração das Séries.

Palavras-chave: elasticidade de Armington; importação; proteção.

Códigos JEL: F13

Estimamos a elasticidade de Armington para os 28 setores industriais da matriz insumo-produto brasileira, no período 1986-2002. A metodologia empregada leva em conta as propriedades estocásticas das séries de dados e os efeitos da liberalização do comercio exterior brasileiro ocorrida em 1990. Obtemos elasticidades significativamente diferentes de zero para 24 setores, cujos valores estimados se situam no intervalo de 0,2 a 3,6 e uma média ponderada de 0,9 . Para três setores a elasticidade estimada não é significativamente diferente de zero e para um setor encontramos uma elasticidade significativa, porém com sinal incorreto.

We estimate the Armington elasticity for the 28 industrial sectors of the Brazilian input-output table, for the period 1986-2002. The methodology we use takes into account the stochastic properties of the data series, and the effects of the Brazilian foreign trade liberalization that occurred in 1990. We obtain statistically significant estimates of the elasticities for 24 sectors, and their estimated values are in the interval 0.2 to 3.6, with a weighted average of 0.9. For tree sectors the estimated elasticity is not significantly different from zero, and for one sector we find a significant elasticity, but it has the wrong sign.

\footnotetext{
*Esta é uma versão revista de Tourinho et alii (2003). Os autores agradecem os comentários e as sugestões de dois pareceristas anônimos.

${ }^{\dagger}$ Banco Nacional do Desenvolvimento Econômico e Social (BNDES), Instituto de Pesquisa Econômica Aplicada (IPEA) e Universidade do Estado do Rio de Janeiro (UERJ). E-mail: tour inho@ipea.gov . br

${ }^{\ddagger}$ Instituto de Pesquisa Econômica Aplicada (IPEA) e da Universidade do Estado do Rio de Janeiro (UERJ). E-mail: kume@ipea . gov.br

$\S$ Instituto de Pesquisa Econômica Aplicada (IPEA), atualmente na NEO Investimentos. E-mail: ana.pedroso@ neoinvestimentos. com.br
} 


\section{INTRODUÇÃO}

A avaliação dos efeitos econômicos dos acordos regionais de livre-comércio, ${ }^{1}$ que envolvem concessões tarifárias recíprocas que afetam muitos setores e têm impactos complexos sobre a economia nacional, pode ser feita utilizando-se modelos computáveis de equilíbrio parcial e de equilíbrio geral. Nesses dois tipos de modelos as alterações nas tarifas modificam o preço internado do bem importado, relativamente ao do bem doméstico, e essa mudança de preços relativos afeta a fração da demanda total atendida pelas importações. Para analisar esse efeito e tentar prevê-lo, são necessárias informações sobre a sua intensidade, que pode ser medida pela elasticidade de substituição entre bens de origem doméstica e importada, denominada elasticidade de Armington na literatura. Ademais, essas elasticidades devem ser desagregadas por setor produtivo, para considerar a diversidade de situações quanto à possibilidade de substituição da produção interna pelas importações.

Entretanto, a maioria dos países não dispõe de estimativas das elasticidades de Armington, apesar de sua crucial importância para avaliar o impacto de medidas de política comercial. É freqüente se observar nos estudos sobre este tema o uso de estimativas feitas para outros países, desconsiderando, em muitos casos, grandes diferenças na estrutura da produção e do consumo desses países. ${ }^{2}$ Como elas também não estão disponíveis para o Brasil, esse trabalho tem como objetivo estimar as elasticidades de Armington para o período 1986-2002, por setor da matriz de insumo-produto do IBGE.

Adicionalmente, a abordagem aqui proposta traz uma contribuição metodológica em relação às técnicas geralmente empregadas na literatura para estimar as elasticidades de Armington, pois a escolha do método de estimação depende da ordem de integração das séries temporais de quantidade e preço relativos. Dependendo da relação entre elas, aplicamos uma dentre quatro abordagens: regressão simples em níveis, equação em primeiras diferenças, equações mistas, ou o modelo vetorial de correção de erros do tipo proposto por Johansen. ${ }^{3}$ Tanto nos testes da ordem de integração como na estimação das equações foi considerada a possibilidade de quebra estrutural por ocasião da liberalização comercial brasileira iniciada em 1990, além da possibilidade de ocorrência de fatores sazonais e da presença de tendência temporal. Na estimação foi também considerada a possibilidade de que a incerteza dos preços afete a demanda por importações. Esta abordagem mais cuidadosa na especificação do modelo tem vantagens empíricas claras no nosso caso, pois a estimação da elasticidade de Armington para o Brasil no período analisado havia se mostrado bastante difícil, quando feita com o uso de métodos mais simples.

Este trabalho está organizado em cinco seções, incluindo esta introdução. Na Seção 2, revemos brevemente o conceito de elasticidade de substituição de Armington e mostramos a metodologia adotada para introduzir o impacto da abertura comercial brasileira iniciada em 1990 sobre o preço do produto importado. Na Seção 3, descrevemos os testes utilizados para determinar a existência de raiz unitária nas séries de preços e de quantidades e os modelos aplicados no processo de estimação. Na Seção 4 mostramos as estimativas da elasticidade de Armington no Brasil. Na Seção 6, resumimos os principais resultados.

\footnotetext{
${ }^{1} \mathrm{O}$ Brasil está envolvido em diversas negociações comerciais, em vários âmbitos e com abrangência variada: multilateral na Organização Mundial do Comércio (OMC); regional — Área de Livre-Comércio das Américas (ALCA) e acordo de livre-comércio entre o Mercosul e a União Européia (UE); e bilateral — África do Sul e Índia, entre outros.

${ }^{2}$ Sánchez (2001), por exemplo, avalia os custos e os benefícios do Mercosul na Alca utilizando o modelo de equilíbrio geral do GTAP (Global Trade Analysis Project), mas multiplica as elasticidades originais por seis. Harrinson e alii (2003) analisam os impactos de acordos comerciais regionais e multilaterais no Brasil, usando as elasticidades estimadas para Hong-Kong.

${ }^{3}$ Acreditamos que esta é uma aplicação pioneira, mesmo na literatura internacional, dos métodos desenvolvidos por Johansen (1988) ao problema de estimação de elasticidades de Armington.
} 


\section{A ELASTICIDADE DE ARMINGTON E A ABERTURA COMERCIAL NO BRASIL}

A abordagem proposta por Armington (1969), inicialmente no contexto de equilíbrio parcial, tem sido amplamente utilizada para avaliar os impactos de alterações na política comercial, tanto em modelos de equilíbrio parcial como nos modelos de equilíbrio geral. ${ }^{4}$ Ela supõe que os produtos são diferenciados segundo o país de origem e que, para cada setor, a demanda total interna é atendida por um bem resultante de uma agregação CES (Constant Elasticity Substitution) entre os bens produzidos domesticamente e importados. Para cada bem, a quantidade ofertada domesticamente do bem composto $i$ é dada pela equação 1 .

$$
Q_{i}=\bar{Q}_{i}\left[\delta_{i} M_{i}^{-\rho_{i}}+\left(1-\delta_{i}\right) D_{i}^{-\rho_{i}}\right]^{\frac{-1}{\rho_{i}}}
$$

onde $Q_{i}, M_{i}$ e $D_{i}$ representam, respectivamente, os índices de quantidade do bem agregado, do produto importado e do bem produzido domesticamente do setor $i, \bar{Q}_{i}$ é o fator de escala, e $\delta_{i}$ e $\rho_{i}$ são parâmetros. O primeiro é o fator de distribuição, cujo papel pode ser visto mais facilmente supondo $\rho_{i}=-1$, quando então o bem composto é apenas uma combinação linear de $M_{i}$ e $D_{i}$. O segundo parâmetro indica o grau de substituição entre os produtos importado e doméstico, e determina o formato da curva de indiferença, que permite a substituição entre esses dois bens.

A solução do problema de minimização do custo de demanda total, dados o dispêndio e os preços dos produtos importado e doméstico, indica a composição ótima desses dois bens para produzir o bem composto $Q_{i}$, que é representada pela equação 2 . Nela se observa que a proporção entre os bens doméstico e importado depende da elasticidade de substituição $\sigma_{i}=\frac{1}{\left(1+\rho_{i}\right)}$ e da razão entre os preços, representados, respectivamente, por $P_{i}^{d}$ e $P_{i}^{m}$.

$$
\frac{M_{i}}{D_{i}}=\left[\left(\frac{\delta_{i}}{1-\delta_{i}}\right)\left(\frac{P_{i}^{d}}{P_{i}^{m}}\right)\right]^{\sigma_{i}}
$$

o preço relevante do produto importado para o consumo no país - denominado preço internado — depende do preço do bem no mercado externo em moeda estrangeira $\left(P_{i}^{e}\right)$, da taxa de câmbio $(X)$ e do imposto de importação $\left(\tau_{i}\right)$, como explicitado na equação 3:

$$
P_{i}^{m}=P_{i}^{e} X\left(1+\tau_{i}\right)
$$

É útil analisar o comportamento da equação 2 para diferentes valores da elasticidade de substituição em três casos extremos. Se $\rho_{i} \rightarrow \infty$ e $\sigma_{i} \rightarrow 0$, não há substituição entre os dois bens, e a razão entre a demanda dos produtos importados e os produzidos internamente independe dos preços relativos. Quando $\rho_{i} \rightarrow-1$ e $\sigma_{i} \rightarrow \infty$, os dois produtos são considerados substitutos perfeitos, ${ }^{5}$ e pequenas variações nos preços relativos são suficientes para promover grandes alterações na razão $\frac{M_{i}}{D_{i}}$. Finalmente, quando $\rho_{i}=0$ e $\sigma_{i}=1$, a função CES na equação 1 se reduz a uma função Cobb-Douglas, e a razão entre o dispêndio nos bens importado e doméstico é constante, e igual a $\frac{\delta_{i}}{\left(1-\delta_{i}\right)}$. A equação 2 mostra, também, que uma estimativa do grau de substituição entre os bens importado e doméstico $\left(\sigma_{i}\right)$ pode ser obtida a partir de séries temporais para as razões $\frac{M_{i}}{D_{i}} \mathrm{e} \frac{P_{i}^{d}}{P_{i}^{m}}$.

Para poder usar equação 2 para estimar $\sigma_{i}$, entretanto, é necessário levar em conta que há um período de tempo necessário para que haja o ajustamento completo das quantidades à mudança de

\footnotetext{
${ }^{4}$ Podemos citar, por exemplo, Dervis et alii (1982) para um modelo-padrão de equilíbrio geral computável (EGC) que utiliza a formulação de Armington e de Melo e Robinson (1989) para uma discussão mais detalhada de sua utilização nesse tipo de modelo. Para utilização em modelos de equilíbrio parcial, veja a série de estudos iniciada por Hufbauer e Elliot (1994) para medir o custo social da proteção em diversos países, patrocinado pelo Institute for International Economics, Washington, D.C.

${ }^{5}$ Neste caso, consideramos que o preço doméstico do bem i é muito sensível ao do competidor importado e a razão entre eles será, aproximadamente, constante.
} 
preços. No curto prazo (alguns meses), o impacto pode ser pequeno, pois em geral é necessário um período mais longo para que variações no preço relativo dos importados se reflitam integralmente nas importações. Como em Gallaway et alii (2003), o nosso interesse neste estudo é nas elasticidades de substituição de longo prazo, pois a utilização mais freqüente das elasticidades de Armington ocorre em análises de estática comparativa, seja em modelos de equilíbrio parcial ou geral. Nesse tipo de abordagem os resultados do experimento controlado são comparados com os valores do ano-base, supondo que o sistema econômico dispõe de um período de ajuste suficientemente longo para que o resultado do experimento reflita os efeitos totais da política que se pretende avaliar.

Para construir uma série de preços dos bens importados que traduza os valores efetivamente pagos pelos importadores para interná-los no Brasil, é necessário levar em conta algumas peculiaridades relativas à tributação do comercio exterior brasileiro entre 1986 e 2002. Para fazer isto, argumentamos que o período de interesse se divide em dois sub-períodos distintos, no que se refere à motivação das importações, como se descreve de modo estilizado a seguir.

Antes do processo de abertura unilateral do Brasil ao comercio exterior, que ocorreu em 1990, as importações se enquadravam, grosso modo, em duas categorias principais:

(a) Importações de produtos não competitivos com a produção doméstica, devido à inexistência de similar nacional, para os quais as tarifas aduaneiras eram positivas, porém baixas. Isto ocorria porque não havia necessidade de proteção à indústria nacional como, por exemplo, para carvão mineral, petróleo, alguns fertilizantes e bens de capital sem similar nacional;

(b) Importações competitivas com a produção nacional, para os quais a alíquota do imposto de importação era extremamente elevada. Neste caso, a importação era viável economicamente apenas quando feita por agentes que conseguiam isenção total (na maioria dos casos) ou parcial da tarifa. Estas importações eram realizadas ao amparo de regimes especiais de tributação como, por exemplo, as realizadas pelas empresas estatais, as vinculadas aos projetos de investimentos que, mesmo conduzidos por empresas privadas, eram consideradas de interesse nacional pelo Conselho de Desenvolvimento Industrial (CDI), pela Superintendência do Desenvolvimento da Amazônia (SUDAM), Superintendência do Desenvolvimento do Nordeste (SUDENE) e as destinadas à produção na Zona Franca de Manaus, etc. Esta é uma situação de demanda reprimida, onde potenciais importadores eram alijados do mercado de importação dos bens cuja tarifa era proibitiva, devido à sua incapacidade de conseguir a isenção tributária. ${ }^{6}$

Essa dicotomia foi conseqüência da crise de balanço de pagamentos que se iniciou em 1983, com a menor disponibilidade de recursos financeiros para os países em desenvolvimento, se agravou em 1987, com a declaração da moratória dos pagamentos de juros da divida externa, e se normalizou apenas em 1992, com o acordo de refinanciamento da divida externa brasileira.

Após 1990, as tarifas nominais foram reduzidas e as importações foram liberalizadas, com a extinção da maioria dos regimes especiais de importação, permanecendo em vigência apenas aqueles vinculados à Zona Franca de Manaus, drawback, informática e acordos internacionais. Neste período, as tarifas efetivamente pagas se aproximaram mais das tarifas legais.

Apresentamos abaixo uma formulação que procura traduzir as situações antes e depois da abertura comercial de modo unificado. Para isto calculamos a tarifa equivalente vista pelo importador médio de cada um dos bens, levando em conta a dicotomia existente entre as duas categorias de importação descritas anteriormente. Admitindo que em cada setor as importações foram determinadas pela condição representada na equação 2 , mas que uma parte delas pagou a tarifa legal correspondente,

\footnotetext{
${ }^{6}$ Segundo Kume (1990), neste período, cerca de 70\% das importações, exclusive petróleo, eram realizadas por meio de regimes especiais de tributação. Além disso, ocorria a presença generalizada de tarifas redundantes, o que dificultava ainda mais as importações competitivas fora dos regimes especiais.
} 
enquanto outra parte ficou isenta, podemos escrever as equações 4 e 5 que refletem, respectivamente, as quantidades importadas em cada uma daquelas situações:

$$
\begin{aligned}
& \frac{\alpha_{i} M_{i}}{D_{i}}=\alpha_{i}\left[\left(\frac{\delta_{i}}{1-\delta_{i}}\right)\left(\frac{P_{i}^{d}}{P_{i}^{e} X}\right)\left(\frac{1}{1+\tau_{i}}\right)\right]^{\sigma_{i}} \\
& \frac{\left(1-\alpha_{i}\right) M_{i}}{D_{i}}=\left(1-\alpha_{i}\right)\left[\left(\frac{\delta_{i}}{1-\delta_{i}}\right)\left(\frac{P_{i}^{d}}{P_{i}^{e} X}\right)\right]^{\sigma_{i}}
\end{aligned}
$$

onde $\alpha_{i}$ denota a proporção de importações que são feitas com pagamento integral de tarifa no setor $i$. A razão entre o total das importações e a produção domestica de cada setor é calculada na equação 6 somando as equações 4 e 5 :

$$
\frac{M_{i}}{D_{i}}=\frac{\alpha_{i} M_{i}}{D_{i}}+\frac{\left(1-\alpha_{i}\right) M_{i}}{D_{i}}=\left[\left(\frac{\delta_{i}}{1-\delta_{i}}\right)\left(\frac{P_{i}^{d}}{P_{i}^{e} X}\right)\right]^{\sigma_{i}}\left[\left(1-\alpha_{i}\right)+\alpha_{i}\left(\frac{1}{1+\tau_{i}}\right)^{\sigma_{i}}\right]
$$

Para estimar a equação 6 é conveniente aplicar a ela a transformação logarítmica, que produz a equação 7:

$$
\log \left(\frac{M_{i}}{D_{i}}\right)=\sigma_{i} \log \left[\left(\frac{\delta_{i}}{1-\delta_{i}}\right)\left(\frac{P_{i}^{d}}{P_{i}^{e} X}\right)\right]+\log \left[\left(1-\alpha_{i}\right)+\alpha_{i}\left(\frac{1}{1+\tau_{i}}\right)^{\sigma_{i}}\right]
$$

A equação 7 contém um termo não-linear na elasticidade de substituição, o que dificulta a sua estimação. Para simplificá-la, tomamos a expansão de Taylor do segundo termo do lado direito de 7 com relação a $\sigma_{i}$, na vizinhança de $\sigma_{i}=1$, e obtemos a equação 8 .

$$
\begin{aligned}
\log \left[\left(1-\alpha_{i}\right)+\alpha_{i}\left(\frac{1}{1+\tau_{i}}\right)^{\sigma_{i}}\right]= & \log \left[\left(1-\alpha_{i}\right)+\left(\frac{\alpha_{i}}{1+\tau_{i}}\right)\right]+ \\
& \frac{\alpha_{i}}{1+\tau_{i}-\alpha_{i} \tau_{i}}\left(\sigma_{i}-1\right) \log \left(\frac{1}{1+\tau_{i}}\right)+\vartheta\left[\sigma_{i}-1\right]^{2}
\end{aligned}
$$

O termo que depende da elasticidade de substituição no lado direito de 8 , além do erro de aproximação, é linear em $\sigma_{i}$, e é apresentado em 9.

$$
\sigma_{i}\left[\theta_{i} \log \left(\frac{1}{1+\tau_{i}}\right)\right] \text {,onde } \theta_{i}=\frac{\alpha_{i}}{1+\tau_{i}-\alpha_{i} \tau_{i}}
$$

Utilizando a expressão em 9 como um valor aproximado para a parte do segundo termo do lado direito da equação 7 que depende de $\sigma_{i}$, obtemos a equação 10 , onde a constante $\kappa_{i}$, definida por 11 , consolida todos os outros termos que são independentes de $\sigma_{i}$.

$$
\begin{aligned}
\log \left(\frac{M_{i}}{D_{i}}\right) & =\kappa_{i}+\sigma_{i} \log \left[\left(\frac{\delta_{i}}{1-\delta_{i}}\right)\left(\frac{P_{i}^{d}}{P_{i}^{e} X}\right)\right]+\sigma_{i} \theta_{i} \log \left(\frac{1}{1+\tau_{i}}\right) \\
\kappa_{i} & =\log \left[\left(1-\alpha_{i}\right)+\left(\frac{\alpha_{i}}{1+\tau_{i}}\right)\right]-\theta_{i} \log \left(\frac{1}{1+\tau_{i}}\right)
\end{aligned}
$$

Finalmente, simplificando, temos a equação 12 , que é similar à equação 2 , mas nela o termo que reflete o efeito da tarifa de importação sobre os preços internados aparece elevado a $\theta_{i}$,

$$
\log \left(\frac{M_{i}}{D_{i}}\right)=\kappa_{i}+\sigma_{i} \log \left[\left(\frac{\delta_{i}}{1-\delta_{i}}\right)\left(\frac{P_{i}^{d}}{P_{i}^{e} X}\right)\left(\frac{1}{1+\tau_{i}}\right)^{\theta_{i}}\right]
$$


Para extrair o significado econômico do expoente $\theta_{i}$ em 12, devemos analisar a expressão que o define, apresentada em 9, e lembrar que $\alpha_{i}$ é a proporção de importações que se fazem com pagamento integral da tarifa nominal $\tau_{i}$. É então trivial verificar que a expressão 12 reflete adequadamente os dois casos estilizados descritos anteriormente quanto à natureza das importações brasileiras antes da abertura comercial, pois eles correspondem aos valores extremos para o valor de $\alpha_{i}$. Quando o bem importado é não-competitivo (caso (a)), a alíquota antes de 1990 era baixa e atingia toda a importação, ou seja, $\alpha_{i}=1$, e então $\theta_{i}=1$ e a equação 12 se reduz à expressão em 4 . Quando o bem importado é competitivo (caso (b)), e a tarifa antes de 1990 era elevada, e as importações que de fato ocorriam eram feitas por agentes que tinham isenção, ou seja, $\theta_{i}=0$, fazendo com que 12 se reduza à equação 5 .

Após a abertura comercial temos para todos os bens situações intermediárias entre aquelas anteriores, extremas, descritas acima, onde uma parte das importações paga a tarifa nominal e a outra parte tem isenção. Elas também são adequadamente representadas por 12, cujo comportamento pode ser extrapolado a partir do exame do valor aproximado de $\theta_{i}$. Ele é dado pela equação 13 , obtida pela expansão em série de Taylor da equação 9 com relação $\alpha_{i}, \tau_{i} \in[0,1]$ na vizinhança da origem. Esta expressão mostra que para valores baixos da tarifa o comportamento de $\theta_{i}$ é dominado por $\alpha_{i}$, enquanto para $\alpha_{i}$ pequeno, ele é dominado pela tarifa $\tau_{i}$.

$$
\theta_{i}=\alpha_{i}+\vartheta\left[\alpha_{i}\right]^{2}+\tau_{i}\left(-\alpha_{i}+\vartheta\left[\alpha_{i}\right]^{2}\right)+\vartheta\left[\tau_{i}\right]^{2}
$$

Para estimar a equação 12 necessitamos ainda de uma medida para $\alpha_{i t}{ }^{7}$ Ela pode ser obtida admitindo que, no contexto da situação estilizada descrita no inicio desta seção, a tarifa média observada é uma média ponderada entre a tarifa nula do caso (b), e a tarifa nominal do caso (a), onde o fator de ponderação é o valor estimado de $\alpha_{i t}$. Isto está representado na equação 14 , onde $\bar{\tau}_{i t}$ representa a tarifa média observada.

$$
\bar{\tau}_{i t}=\alpha_{i t} \tau_{i t}
$$

A partir de 14 obtém-se em 15 a estimativa de $\alpha_{i t}$, que é representada por $\tilde{\alpha}_{i t}$.

$$
\tilde{\alpha}_{i t}=\bar{\tau}_{i t} / \tau_{i t}
$$

Por último, incorporamos nas equações estimadas uma variável dummy para representar o deslocamento da curva de demanda de importações provocado pelo livre acesso às importações feitas com pagamento integral da tarifa de importação, a partir do último trimestre de $1990 .^{8}$

A esta altura o leitor pode estar se perguntando qual o motivo de tanto esforço no tratamento da abertura comercial, visto que ele permite incorporar ao estudo os dados de um período de apenas cinco anos (de 1986 a 1990). A principal razão não é propriamente o aumento de graus de liberdade das regressões, mas principalmente a inclusão na análise empírica de um período em que houve grande variação do preço internado dos bens importados, relativamente aos bens domésticos, por conta principalmente da redução das tarifas de importação. Isto é importante porque o objeto deste estudo é justamente a estimação da curvatura da curva da curva de indiferença da equação CES em (1), que só pode ser medida corretamente se dispusermos de uma base de dados que incorpore uma gama variada de preços relativos das duas categorias de bens.

\footnotetext{
${ }^{7} \mathrm{Na}$ notação para $\alpha_{i}$ foi introduzido o índice $t$, para ressaltar que aquele parâmetro, que é tomado como exógeno nesta formulação, varia no tempo.

${ }^{8}$ As restrições às importações foram extintas oficialmente em março de 1990 com a posse do novo governo. No entanto, as barreiras não-tarifárias tais como o limite de importação anual por empresa e a emissão livre das guias de importação, que de fato controlavam as compras externas, foram efetivamente retiradas apenas em julho do mesmo ano. Assim, dado o longo período de forte controle das importações, a reação das empresas frente ao novo regime comercial só ocorreu a partir do último trimestre daquele ano.
} 


\section{ANÁLISE EMPÍRICA}

Os dados utilizados são trimestrais, no período 1986-2002, por setor da matriz de insumo produto do Brasil (nível 50), produzida pelo IBGE. A base de dados em formato eletrônico está disponível para os leitores, a pedido, e a sua construção está descrita no Apêndice A. ${ }^{9}$

Para estimar a equação 12, é necessário examinar primeiramente a ordem de integração das séries envolvidas. A relação entre as características estocásticas destas séries, assim obtida, determinou o modelo que foi estimado para obter a elasticidade de substituição. Esta seção descreve as duas etapas do procedimento empírico adotado.

Para implementar o teste da raiz unitária de modo sistemático, no que se refere à inclusão da constante e da tendência temporal, utilizamos o procedimento proposto por Dolado et alii (1990), com um nível de significância de $10 \% .{ }^{10} \mathrm{O}$ número de defasagens utilizado nos testes foi escolhido endogenamente pelo critério de informação de Akaike. Nos casos em que os resultados destes testes indicaram a existência de uma raiz unitária, levamos também em conta de que este resultado poderia ser conseqüência de uma quebra estrutural em uma série que, de fato, fosse estacionária. Para testar esta possibilidade, aplicamos o teste de Perron (1989) com nível de significância de 10\%, e admitimos que a quebra estrutural teria ocorrido no quarto trimestre de 1990 que seria do tipo representado pelo changing growth model, segundo a tipologia lá proposta. ${ }^{11} \mathrm{O}$ conjunto de procedimentos empregados nesta etapa está detalhado no Apêndice B.

Para explicitar a metodologia de estimação, relembramos que a equação 12 é uma relação de longo prazo entre $p_{i t}$ e $q_{i t}$, definidas em 16 a 19:

$$
\begin{gathered}
q_{i t}=\log \left(\frac{M_{i t}}{D_{i t}}\right) \\
p_{i t}=\log \left[\left(\frac{P_{i t}^{d}}{P_{i t}^{e} X}\right)\left(\frac{1}{1+\tau_{i t}}\right)^{\theta_{i t}}\right] \\
\theta_{i t}=\tilde{\alpha}_{i t} /\left(1+\tau_{i t}-\tilde{\alpha}_{i t} \tau_{i t}\right) \\
\tilde{\alpha}_{i t}=\bar{\tau}_{i t} / \tau_{i t}
\end{gathered}
$$

A versão estocástica da equação 12 é representada em 20 onde, para simplificar a notação, deixamos de utilizar o índice de produto $i$. Esta convenção será seguida deste ponto em diante, e se justifica pelo fato de aplicamos a mesma metodologia a todos os setores. A estimação da elasticidade é feita para cada um dos produtos aqui considerados individual e isoladamente, para que seja consistente com a hipótese de Armington onde as elasticidades cruzadas são nulas.

\footnotetext{
${ }^{9} \mathrm{~A}$ base de dados deste estudo é diferente daquela em Tourinho et alii (2003), porque em meados de 2002 foi divulgada uma revisão nas estatísticas de comércio exterior de 1996 (FUNCEX, 2002). Os dados de exportação não sofreram alterações importantes, mas para vários setores a despesa de importação foi alterada de forma significativa devido, principalmente, a modificações na quantidade física importada. Como os índices de preço e quantum estimados pela Funcex são encadeados tendo como período base justamente o ano de 1996, todos eles foram revistos. Assim, a mudança naquele ano afetou o nível de toda a série, embora as taxas de variação não tenham sofrido mudanças, à exceção daquelas calculadas em relação a 1996.

${ }^{10} \mathrm{O}$ nível de significância do teste ADF indica a probabilidade de rejeitar a existência da raiz unitária quando ela de fato está presente. Foi adotado dos testes o nível de $10 \%$ como uma solução de compromisso, devido à já bem conhecida propriedade de baixa potência das estatísticas $\mathrm{ADF}$, ou seja, o viés favorável à não-rejeição da raiz unitária quando ela de fato não está presente. Um nível de significância menor reduziria ainda mais a potência do teste nesta amostra relativamente pequena.

${ }^{11} \mathrm{O}$ teste de Perron no caso do changing growth model supõe, na hipótese nula, a existência de raiz unitária com mudança no intercepto do processo no instante de quebra estrutural. Já na hipótese alternativa ele supõe que o processo seja estacionário com mudança na inclinação da linha de tendência determinística no momento da quebra.
} 
Tabela 1 - Tabela de Decisão para o tipo de Modelo a ser Estimado $^{a}$

\begin{tabular}{ccc}
\hline & \multicolumn{2}{c}{$\operatorname{Preços~}(p)$} \\
Quantidades $(q)$ & $\mathrm{I}(0)$ & $\mathrm{I}(1)$ \\
\hline $\mathrm{I}(0)$ & A: níveis & C: níveis \\
$\mathrm{I}(1)$ & B: diferenças & D e E: co-integração \\
\hline
\end{tabular}

${ }^{a}$ Fonte: Elaboração própria.

$$
q_{t}=\mu+\sigma p_{t}+\varepsilon_{t} \quad \text { onde } \quad \mu=\kappa+\sigma \log \left(\frac{\delta}{1-\delta}\right) \quad \text { e } \quad \varepsilon_{t}: N\left(0, v^{2}\right) \varepsilon_{t} \quad \text { é } \quad N(0, \Omega)
$$

Cada uma das series pode ser ou não ser integrada. Caso não haja raiz unitária, a série pode ser estacionária ou não, mas o procedimento adotado é idêntico nesses dois casos, e derivado na hipótese de que a série é estacionária. As quatro possibilidades de combinações possíveis quanto à ordem de integração das séries para $p$ e $q$, e os modelos utilizados em cada um dos casos são apresentados na Tabela 1. Como $q$ é a variável dependente na equação 20 , é a sua ordem de integração que determina se a estimação é feita em níveis ou diferenças, como se verifica comparando as linhas da Tabela 1

Para qualquer dos modelos inclui-se também na equação a ser estimada o coeficiente de variação da razão dos preços $(p)$ como variável exógena, para permitir que a incerteza do preço relativo venha a afetar a razão entre a quantidade importada e a produção domestica. ${ }^{12}$ Não existe uma expectativa a priori quanto à presença desse efeito na equação, nem quanto ao sinal de seu coeficiente, porque ele traduz a interação entre efeitos especulativos de impactos opostos. Por exemplo, empresas que dependem de insumos importados podem reagir a um aumento de incerteza no seu custo relativo antecipando importações (efeito positivo), ou substituindo estes insumos (efeito negativo).

Em adição utilizamos também variáveis de controle para levar em conta alguns fatores exógenos importantes. A primeira delas é uma dummy, que assume os valores $d_{t}=1$ para $t \geq 1990: 4$ e $d_{t}=0$ nos outros períodos, e visa incorporar os efeitos já discutidos da liberalização do comercio exterior em 1990. A segunda é um termo de tendência temporal $(t)$, para capturar outros fatores que possam ter provocado mudanças estruturais no quantum de importações que não foram devidas à variação do preço relativo. A terceira é um vetor de dummies sazonais $\left(z_{t}\right)$.

A inclusão na equação da tendência temporal e da dummy de abertura pode ser racionalizada também como uma tentativa de levar em conta variações na qualidade dos bens e na composição dos agregados de preços e quantidades que não puderam ser adequadamente consideradas na construção dos respectivos índices. É o caso, por exemplo, das importações de bens eletro-eletrônicos, particularmente de computadores pessoais, que aumentaram muito nos últimos anos da amostra, e onde há grande variação das características e composição dos bens agregados. A formulação empregada supõe que parte dessas mudanças ocorreu de maneira progressiva ao longo do período, enquanto outra parte ocorreu de modo abrupto como conseqüência da mudança de regime de comércio exterior, e permite que o procedimento de estimação distribua tais efeitos entre aquelas variáveis.

Finalmente, a equação estimada é a expressão 21 , que inclui todos os efeitos discutidos acima.

$$
q_{t}=\mu+\sigma p_{t}+\lambda d_{t}+\xi \cdot z_{t}+\gamma t+\varepsilon_{t}
$$

\footnotetext{
${ }^{12}$ O coeficiente de variação é a razão entre o desvio padrão e a média da variável, e foi escolhido como indicador de incerteza por preservar o caráter adimensional da equação 20 .
} 
Na estimação de todos os modelos mencionados na Tabela 1 partimos da especificação mais geral, admitindo o numero máximo de defasagens da variável preço, e em seguida eliminamos sucessivamente as variáveis não-significativas, para obter a equação final. A seguir descrevemos a estimação em cada um dos modelos mencionados na Tabela 1.

\subsection{Modelo A}

O caso mais simples ocorre quando ambas as séries são estacionárias, e a elasticidade de longo prazo em (21) pode ser obtida por regressão das variáveis em níveis. A equação é estimada inicialmente através de mínimos quadrados ordinários, sendo novamente estimada pelo método da máxima verossimilhança - admitindo uma estrutura auto-regressiva de primeira ordem para os erros - caso os resíduos ainda apresentem correlação serial de primeira ordem. Neste caso estimamos a elasticidade de Armington de longo prazo como $\frac{\hat{\sigma}}{(1-\hat{\rho})}$, onde $\hat{\rho}$ é o valor estimado para a correlação serial do erro. Aqui, e no restante deste artigo, estamos usando um acento circunflexo sobre a variável para indicar seu valor estimado.

No caso em que o procedimento acima indica a possibilidade de existência de raiz unitária nos resíduos $(\hat{\rho} \approx 1)$, a equação é novamente estimada em primeiras diferenças, na forma da equação 22 . Note-se que ela inclui defasagens da variável de preço entre as explicativas, com um número de defasagens igual àquele determinado no procedimento do teste das propriedades de integração da série, que pode ser nulo. ${ }^{13}$

$$
\Delta q_{t}=\mu+\sigma \Delta p_{t}+\sum_{l=0}^{\tau} \nu_{l} p_{t-l}+\lambda d_{t}+\xi \cdot z_{t}+\gamma t+\varepsilon_{t}
$$

\subsection{Modelos B e C}

Os casos em que a ordem de integração das duas séries não coincide são difíceis de racionalizar economicamente. Além disso, a estimação dessas equações não-balanceadas é bastante incômoda. Essa dificuldade é lembrada por outros autores, que, no entanto, reconhecem a necessidade de contornála da melhor maneira possível. ${ }^{14}$ Indicamos a seguir como tratamos os dois casos onde este modelo aparece na Tabela 1.

Quando $q$ é I(1) e $p$ é I(0), a estimação é feita em primeiras diferenças, como indica a equação (22), o que evita a possibilidade ocorrência de correlação espúria, pois a diferenciação produz séries estacionárias. ${ }^{15}$ Quando $q$ é I(0) e $p$ é I(1), estimamos a equação em níveis, incluindo tantas defasagens da variável preço quanto àquelas utilizadas no teste da ordem de integração da série e mais uma, como indicado em 23.

$$
q_{t}=\mu+\sigma p_{t}+\sum_{l=0}^{\tau+1} \nu_{l} p_{t-l}+\lambda d_{t}+\xi \cdot z_{t}+\gamma t+\varepsilon_{t}
$$

Este tratamento assimétrico destes dois casos se justifica pela natureza da variável dependente, que tem que ser diferenciada, quando ela é integrada. Esta diferenciação, por sua vez, não traz prejuízo à estimação quando a variável preço já é estacionária, e preserva a possibilidade de interpretar o coeficiente dela como a elasticidade.

\footnotetext{
${ }^{13}$ O Apêndice B mostra como o número de defasagens utilizado para o teste ADF foi obtido endogenamente, através de uma seqüência de testes encadeados.

${ }^{14}$ Veja, por exemplo, Madalla e Kim (1998, p. 252): "Should one estimate unbalanced equations? of course not, if it can be avoided. But if it has to be done, one has to be careful in their interpretation and use appropriate critical values".

${ }^{15}$ Este procedimento foi também adotado por Gallaway et alii (2003).
} 
Se na estimação da equação 23 há indicações de existência de correlação serial dos resíduos, dá-se a ela o mesmo tratamento adotado no caso do Modelo A neste caso, ou seja, estimação por quasediferenças (equação 22).

Quando o procedimento descrito acima é incapaz de identificar uma elasticidade de substituição significativamente diferente de zero, tentamos estimar a equação utilizando o método de co-integração, caso que denominamos modelo E. Este procedimento é adotado apesar do teste da ordem de integração das séries não ter indicado que ambas fossem $\mathrm{I}(1)$, mas se justifica por dois motivos. O primeiro é que existe uma margem de erro nos testes de ordem de integração descritos no inicio desta seção e no Apêndice $B$, que pode ter levado à rejeição da raiz unitária para uma das séries, quando ela de fato está presente. O segundo motivo é aquele já mencionado anteriormente: não existe procedimento inteiramente satisfatório de estimação para o caso das equações não balanceadas, e qualquer das opções representa um compromisso, o que justifica a tentativa de estimação por co-integração quando os outros métodos falham em identificar uma elasticidade significativa.

\subsection{Modelo D e E}

Quando preços e quantidades são integrados, a elasticidade de Armington de longo prazo pode ser obtida da relação de co-integração, e para estimá-la utilizamos a abordagem proposta por Johansen (1988). Para fazer isto escrevemos a equação (20) em notação vetorial na equação (24), onde $x_{t}^{\prime}=$ $\left(p_{t}, q_{t}\right), \beta^{\prime}=(1,-\sigma)$ :

$$
\beta^{\prime} x_{t}-\mu=\varepsilon_{t}
$$

Este modelo VAR pode, por sua vez, ser escrito na forma restrita de um modelo de correção de erros (VEC) que, no caso em que não há tendência temporal e que se utiliza apenas uma defasagem, pode ser descrito por (25):

$$
\Delta x_{t}=\alpha \cdot\left(\beta^{\prime} x_{t-1}-\mu\right)+\varepsilon_{t}
$$

onde $\beta$ é o vetor de co-integração, e $\alpha$ é um vetor que indica como a relação de co-integração (o termo entre parênteses) é utilizada para ajustar o valor de $x$, ou seja, é o vetor de coeficientes do termo de correção de erro. $O$ vetor de resíduos $\varepsilon_{t}$ deve ser i.i.d. com média zero e variância $\Omega$.

O VEC em (25) pode ser escrito de modo mais geral como a equação 26 incluindo $k$ defasagens da primeira diferença do vetor das variáveis, e incorporando as variáveis exógenas utilizadas para obter (21): a dummy que captura a liberalização do comércio, a tendência temporal, e as dummies sazonais:

$$
\Delta x_{t}-\gamma=\alpha\left[\beta^{\prime} x_{t-1}-\left(\beta^{\prime} \gamma \cdot(t-1)+\lambda d_{t}+\mu\right)\right]+\sum_{l=1}^{k-1} \Gamma_{l}\left(\Delta x_{t-l}-\gamma\right)+\varepsilon_{t}
$$

As matrizes $\Gamma_{\tau}$ são $2 \times 2$, e fornecem os pesos das componentes auto-regressivas do processo. 0 número de defasagens a serem incluídas na equação, representadas por $l$, foi escolhido de modo a maximizar a estatística de verossimilhança da equação. ${ }^{16}$ Na equação $26, \gamma$ é um vetor $2 \times 1$, cujas componentes traduzem a tendência temporal de crescimento das variáveis. Portanto, o termo $\beta^{\prime} \gamma \cdot(t-$ 1) é um escalar que mostra como elas são compostas para produzir uma tendência temporal na relação de co-integração.

Como a relação de co-integração (o termo entre colchetes na equação 26) foi normalizada com relação às quantidades, ${ }^{17}$ pode-se interpretar a soma dentro dos parênteses como o efeito de longo prazo

\footnotetext{
${ }^{16} \mathrm{O}$ procedimento adotado foi reduzi-lo progressivamente a partir de um valor máximo arbitrário de oito trimestres, correspondentes a dois anos, admitindo que neste período a maior parcela dos efeitos de um choque já teria sido absorvida pelo sistema.

${ }^{17} \mathrm{O}$ coeficiente da primeira componente de $\mathrm{x}$ em ? é unitário, como se vê na equação (24).
} 
Tabela 2 - Tipologia das Séries de Quantum e de Preços ${ }^{a}$

\begin{tabular}{cccc}
\hline Código & Tipo & \multicolumn{2}{c}{ Número de séries } \\
\cline { 3 - 4 } & & Quantum & Preço \\
\hline 1 & Estacionária em torno de uma média não-nula & 2 & 3 \\
2 & Estacionária em torno de uma média nula & - & 1 \\
3 & Estacionária em torno de uma tendência linear & 4 & 1 \\
4 & Tem uma raiz unitária com tendência temporal nula & 10 & 17 \\
5 & Tem uma raiz unitária com tendência temporal não-nula & - & - \\
6 & Não se pode rejeitar a existência de raiz unitária & 2 & - \\
7 & Não tem raiz unitária & 10 & 6 \\
- & Séries com evidencia de quebra estrutural & 10 & 6 \\
\hline
\end{tabular}

${ }^{a}$ Fonte: Elaboração própria.

que seria produzido caso o parâmetro de distribuição na formulação CES da equação 1 tivesse uma tendência temporal, e fosse dependente do regime de comércio exterior. Essa dependência aparece através da dummy de abertura $d_{t}$, definida anteriormente. Para ver isso, pode-se representar esse parâmetro de distribuição generalizado por $\delta_{t}$ e defini-lo de modo implícito pela equação (27):

$$
\log \left[\frac{\delta_{t}}{\left(1-\delta_{t}\right)}\right]=\beta^{\prime} \gamma \cdot(t-1)+\lambda d_{t}+\mu
$$

Portanto, a equação (26) considera as importantes modificações que possam ter ocorrido na equação de demanda de importações, condicionado à hipótese de que a elasticidade de substituição $\sigma$ tenha sido constante por todo o período.

\section{RESULTADOS}

O procedimento descrito na seção anterior para identificação das propriedades das séries, e para a escolha do modelo de estimação adequado, foi aplicado aos setores da matriz de insumo-produto cujo volume importado em 2002 foi significativo, excluindo agropecuária e serviços, totalizando 28 setores.

A classificação adotada para as características estocásticas das séries é descrita na Tabela 2, que também apresenta a freqüência dos tipos de séries encontrados. Verifica-se que 16 séries de quantum e 11 de preços não têm raiz unitária, mas destas apenas seis de quantum e cinco de preços são estacionárias. Há 10 séries de quantum e 17 de preços para as quais se constatou a existência de raiz unitária. ${ }^{18}$ Para duas séries de quantum não se pode rejeitar a existência de raiz unitária. Finalmente, há evidências de quebra estrutural no quarto trimestre de 1990 para 10 séries de quantum e seis de preços.

Considerando a classificação de tipo de modelo da Tabela 1, verifica-se que a maioria dos casos se refere às situações em que a ordem de integração dos preços e quantidades coincide: ocorreram 11 casos do modelo A (estimação em níveis) e 11 do modelo D (estimação por co-integração). Há seis casos de equações não-balanceadas, mas quatro deles foram estimadas com metodologia de co-integração (denominado modelo $E$ ) porque para eles os modelos $B$ e $C$ não produziram estimativas significativamente diferentes de zero para a elasticidade. Há dois casos onde os modelos B e C foram satisfatórios: um de cada um destes dois tipos.

\footnotetext{
${ }^{18}$ É possível apresentar argumentos teóricos contra a possibilidade de uma série de preço ser integrada. Admite-se que, como elas se comportam como tal na nossa amostra, é preferível, para estimação, tratá-las como I(1).
} 
Os resultados são apresentados na Tabela 3, onde se verifica que a elasticidade de Armington estimada tem o sinal correto, sendo significativas ao nível de $5 \%$ para 20 setores, ao nível de $10 \%$ para dois setores e ao nível de $20 \%$ para dois setores. ${ }^{19}$ Para um setor o valor estimado é significativo, porém tem o sinal incorreto (negativo). Para os três setores restantes a elasticidade estimada não é significativamente diferente de zero. Verifica-se também que apenas $12,2 \%$ do valor importado (média no período 1997-2002) foi de bens cuja elasticidade é nula ou negativa (vide sétima coluna). Portanto, pode-se dizer que a maior parte das importações naquele período foi de bens cuja proporção importada responde ao seu preço relativo, confirmando o acerto da utilização formulação de Armington para caracterizar o comportamento das importações do Brasil. A estimativa pontual da elasticidade de substituição, quando positiva e não nula, varia de 0,16 a 3,6, com uma média ponderada pelas importações de 0,93 .

Pode-se notar também, comparando as colunas seis e oito da Tabela 3, que há uma associação entre a ordem de grandeza da elasticidade estimada e o modelo adotado, pois, de um modo geral, as elasticidades maiores foram geradas pelo modelo D (co-integração), as intermediárias pelo modelo $\mathrm{A}$ (níveis), enquanto as equações não balanceadas (modelos B, C e E) produziram as elasticidades menores. Isto já era esperado, pois a coincidência da ordem de integração das séries já é uma indicação de uma associação mais forte entre elas.

O coeficiente de variação dos preços se revelou significativo em apenas dois setores, e em ambos o sinal é positivo, indicando um aumento da proporção importada em resposta a uma elevação da incerteza do preço das importações relativamente aos domésticos. A ausência de significância desta variável na maioria dos setores foi um resultado de certo modo surpreendente, pois esperávamos que fosse significativo para um maior número de setores.

A variável dummy para quebra estrutural em 1990:4 se mostrou significativa aos níveis de $5 \%$ em 11 setores e de $10 \%$ em um, o que confirma a importância das considerações feitas na Seção 2 com relação à natureza do impacto sobre as importações da abertura da economia ocorrida em 1990. O seu coeficiente é positivo em oito setores, onde ela provocou um aumento da proporção de importações em relação à produção doméstica e é negativo nos quatro restantes. Para interpretar corretamente o coeficiente desta variável é importante recordar que uma parte do impacto da liberalização do comercio exterior que se deu por via da redução de tarifas já está incorporada ao valor estimado da elasticidade de Armington. A variável dummy captura a parcela restante que pode ser atribuída a outros fatores tais como a existência de demanda reprimida por importações, cuja materialização se tornou possível pela redução das barreiras não-tarifárias que ocorreram naquela ocasião. ${ }^{20}$

O coeficiente da variável que representa a tendência temporal foi significativo em 20 setores, sendo positivo em todos, exceto em um. Isto é coerente com a interpretação que no período analisado houve um aumento da demanda relativa por importações que não se explica pelos outros três fatores, podendo estar relacionado com a modernização e a internacionalização da composição dos bens produzidos e consumidos no país.

A Tabela 4 sintetiza os valores obtidos para a elasticidade de Armington, mostrando como os setores se distribuem segundo faixas caracterizadas pelo valor respectivo e são denominadas: muito alta, alta, média, baixa, nula, ou negativa. A amplitude da elasticidade em cada classificação não é uniforme porque ela visa fornecer uma indicação do grau de curvatura da curva de indiferença entre importações e produção domestica, e esta não varia linearmente com relação àquele parâmetro, como se verifica na Figura 1

\footnotetext{
${ }^{19}$ A adoção de um nível de significância não-convencional de $20 \%$ para as elasticidades cujo valor estimado é próximo de zero é justificada mais adiante no texto, quando da discussão da Figura 1.

${ }^{20}$ Este é, possivelmente, o caso de automóveis caminhões e ônibus, máquinas e tratores, outros veículos e autopeças, têxtil e artigos para vestuário. Os casos em que o valor estimado do coeficiente daquela variável é negativo são aqueles em que as importações não cresceram tanto quanto se poderia antecipar á vista da redução de tarifas, o que poderia ter ocorrido, por exemplo, devido a iniciativas de defesa de mercado praticadas por borracha, equipamentos eletrônicos, químicos diversos e extrativa mineral.
} 


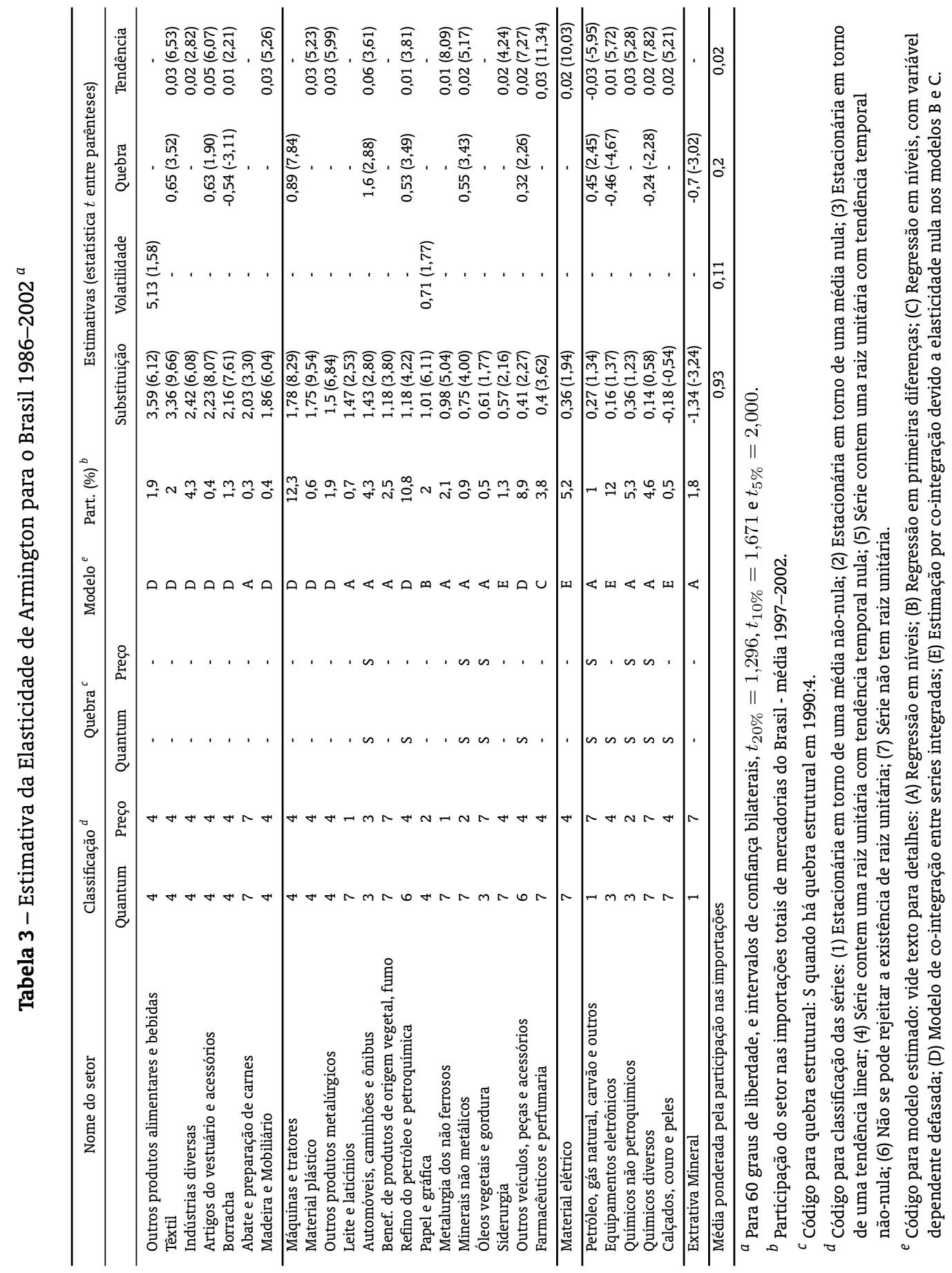


Tabela 4 - Comparação das Elasticidades Obtidas com as da Experiencia Internacional ${ }^{a}$

\begin{tabular}{|c|c|c|c|c|c|c|}
\hline \multirow[t]{2}{*}{ Setor } & \multicolumn{3}{|c|}{ Este Estudo } & \multicolumn{3}{|c|}{ USITC e GTAP } \\
\hline & Nome & Definição & Elasticidade & Média & USITC & GTAP \\
\hline $\begin{array}{l}\text { Outros produtos alimentares e } \\
\text { bebidas } \\
\text { Têxtil }\end{array}$ & Muito alta & $\sigma \geq 3$ & $\begin{array}{l}3,59 \\
3,36\end{array}$ & $\begin{array}{l}3,2 \\
2,3\end{array}$ & $\begin{array}{l}4,2 \\
2,3\end{array}$ & $\begin{array}{l}2,2 \\
2,2\end{array}$ \\
\hline $\begin{array}{l}\text { Indústrias diversas } \\
\text { Artigos do vestuário e acessó- } \\
\text { rios } \\
\text { Borracha } \\
\text { Abate e preparação de carnes } \\
\text { Madeira e Mobiliário } \\
\text { Máquinas e tratores } \\
\text { Material plástico } \\
\text { Outros produtos metalúrgicos }\end{array}$ & Alta & $1,5 \leq \sigma<3$ & $\begin{array}{c}2,42 \\
2,23 \\
2,16 \\
2,03 \\
1,86 \\
1,78 \\
1,75 \\
1,5\end{array}$ & $\begin{array}{c}2,3 \\
3,2 \\
2 \\
2,5 \\
2,8 \\
2,5 \\
2 \\
3,5\end{array}$ & $\begin{array}{c}1,7 \\
2 \\
2 \\
2,7 \\
2,8 \\
2,2 \\
2 \\
4,1\end{array}$ & $\begin{array}{l}2,8 \\
4,4 \\
1,9 \\
2,2 \\
2,8 \\
2,8 \\
1,9 \\
2,8\end{array}$ \\
\hline $\begin{array}{l}\text { Leite e laticínios } \\
\text { Automóveis, caminhões e ôni- } \\
\text { bus } \\
\text { Beneficiamento de produtos de } \\
\text { origem vegetal, fumo } \\
\text { Refino do petróleo e petroquí- } \\
\text { mica } \\
\text { Papel e gráfica } \\
\text { Metalurgia dos não ferrosos } \\
\text { Minerais não metálicos } \\
\text { Óleos vegetais e gordura } \\
\text { Siderurgia }\end{array}$ & Média & $0,5 \leq \sigma<1,5$ & $\begin{array}{l}1,47 \\
1,43 \\
1,18 \\
1,18 \\
\\
1,01 \\
0,98 \\
0,75 \\
0,61 \\
0,57\end{array}$ & $\begin{array}{c}3,6 \\
4 \\
3,3 \\
2,2 \\
\\
2,9 \\
3,6 \\
2,7 \\
3,6 \\
3,5\end{array}$ & $\begin{array}{c}5 \\
2,7 \\
3,5 \\
2,5 \\
\\
3,9 \\
4,4 \\
2,5 \\
5 \\
4,1\end{array}$ & $\begin{array}{l}2,2 \\
5,2 \\
3,1 \\
1,9 \\
1,8 \\
2,8 \\
2,8 \\
2,2 \\
2,8\end{array}$ \\
\hline $\begin{array}{l}\text { Outros veículos, peças e acessó- } \\
\text { rios } \\
\text { Farmacêuticos e perfumaria } \\
\text { Material elétrico } \\
\text { Petróleo, gás natural, carvão } \\
\text { Equipamentos eletrônicos }\end{array}$ & Baixa & $0<\sigma<0,5$ & $\begin{array}{c}0,41 \\
0,4 \\
0,36 \\
0,27 \\
0,16\end{array}$ & $\begin{array}{c}4 \\
2 \\
2,5 \\
2,8 \\
2,7\end{array}$ & $\begin{array}{c}2,7 \\
2 \\
2,2 \\
2,8 \\
2,6\end{array}$ & $\begin{array}{l}5,2 \\
1,9 \\
2,8 \\
2,8 \\
2,8\end{array}$ \\
\hline $\begin{array}{l}\text { Químicos não petroquímicos } \\
\text { Químicos diversos } \\
\text { Calçados, couro e peles }\end{array}$ & Nula & $\sigma \approx 0$ & $\begin{array}{l}0 \\
0 \\
0\end{array}$ & $\begin{array}{c}2 \\
2 \\
3,1\end{array}$ & $\begin{array}{c}2 \\
2 \\
1,7\end{array}$ & $\begin{array}{l}1,9 \\
1,9 \\
4,4\end{array}$ \\
\hline Extrativa Mineral & Sinal incorreto & $\sigma<0$ & $-1,34$ & 2,4 & 2 & 2,8 \\
\hline $\begin{array}{l}\text { Media aritmética * } \\
\text { Mínimo } \\
\text { Máximo } \\
\text { Amplitude } \\
\text { Desvio padrão * }\end{array}$ & & & $\begin{array}{c}1,24 \\
0 \\
3,59 \\
3,59 \\
0,98\end{array}$ & $\begin{array}{c}2,8 \\
2 \\
4 \\
2 \\
0,6\end{array}$ & $\begin{array}{c}2,8 \\
1,7 \\
5 \\
3,3 \\
1\end{array}$ & $\begin{array}{l}2,8 \\
1,8 \\
5,2 \\
3,4 \\
0,9\end{array}$ \\
\hline
\end{tabular}

${ }^{a}$ Fonte: Donnelly (2004) e elaboração própria.

* exclusive setor com elasticidade de sinal incorreto 
Figura 1 - Curvas de indiferença entre importações e produção doméstica

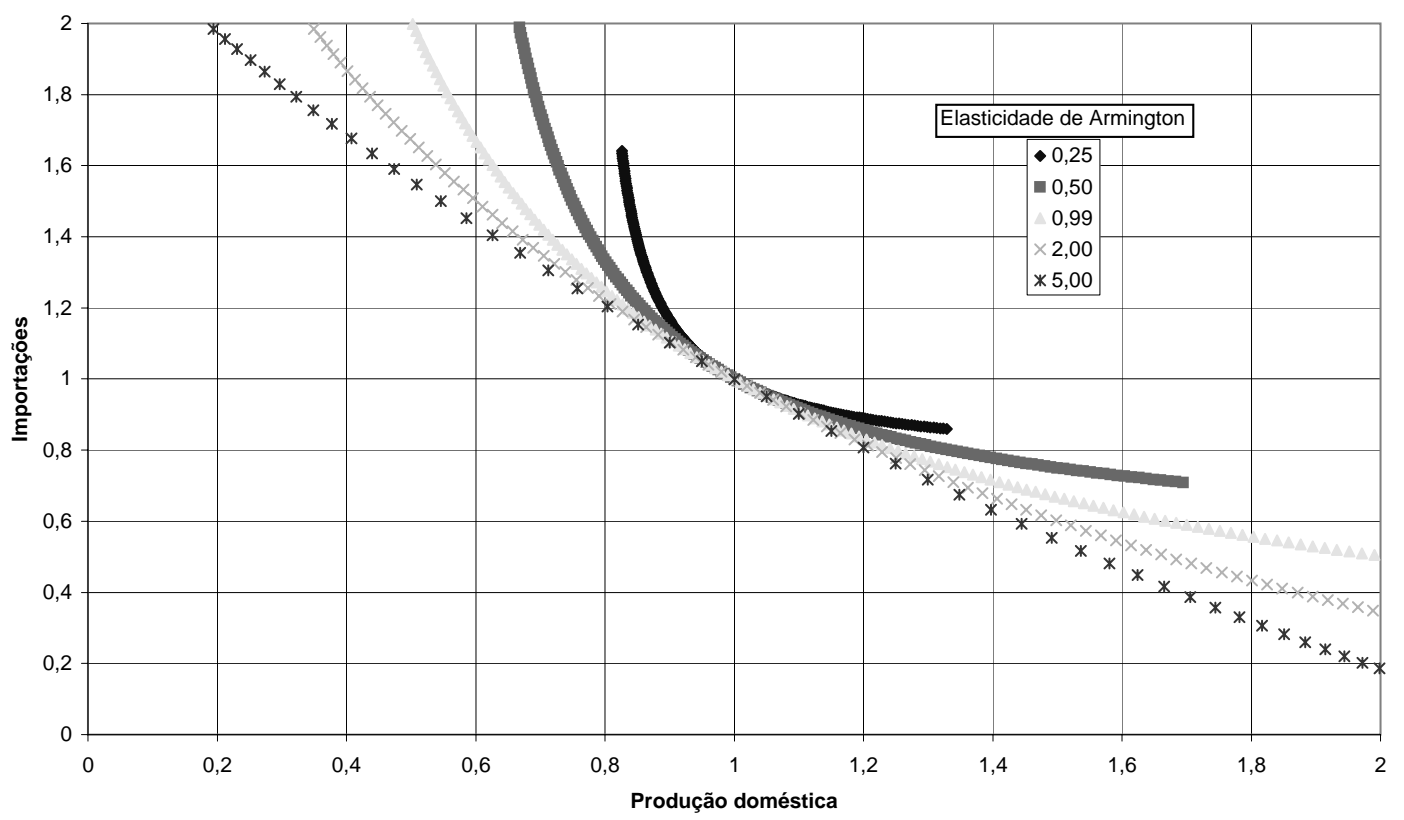

A Figura 1 é também útil para ilustrar a natureza da dificuldade de estimação da elasticidade de substituição quando o seu valor é pequeno, e a curvatura da curva de indiferença é elevada, como nos dois casos em ela é baixa e nos três casos em que ela não é significativamente diferente de zero. Lembrando que em qualquer ponto a elasticidade de substituição é a razão entre a inclinação da curva de indiferença que passa por ele e a inclinação do segmento de reta que o liga à origem do sistema de coordenadas, nota-se que naqueles casos o trecho da curva de indiferença que é percorrido na amostra é relativamente restrito, mesmo que haja uma variação ampla de preços relativos. Isto dificulta a estimação porque grandes variações de $p$ produzirão apenas variações pequenas de $q$, e nesta situação será maior a importância relativa do erro $\varepsilon$ da equação (21). Pode-se esperar, portanto, que naqueles casos o desvio padrão da estimativa de $\sigma$ seja elevado.

A Tabela 4 mostra que há dois setores com elasticidade muito alta $(\sigma \cong 3)$, oito com elasticidade alta $(\sigma \cong 2)$, nove com elasticidade média $(\sigma \cong 1)$, cinco com elasticidade baixa $(\sigma<0,5)$, três com elasticidade nula e um com elasticidade negativa. A média aritmética é 1,24, e a distribuição de freqüência é aproximadamente simétrica.

Em seguida, procuramos comparar as nossas estimativas de elasticidade com as disponíveis em outros estudos. Como foi dito anteriormente, não há estimativas para o Brasil e a comparação com as de outros países é dificultada pelas diferenças no nível de classificação setorial adotado no pequeno número de estudos disponíveis na literatura internacional. Entretanto, essa restrição pode ser contornada com o trabalho de Donnelly (2004), que mostram as elasticidades de substituição adotadas nos modelos de equilíbrio geral computável da USITC e do $\mathrm{GTAP}^{21}$ com uma estrutura de setores próxima àquela

${ }^{21}$ A United States International Trade Commission (USITC) desenvolveu um modelo de equilíbrio geral computável para os Estados Unidos, e o utiliza para avaliar os impactos na economia americana das mudanças na política comercial. As elasticidades extraídas dele se referem aos EUA, e foram coletadas na literatura, e posteriormente ajustadas por especialistas setoriais. 0 Global Trade Analysis Project (GTAP) desenvolveu um modelo multi regional de abrangência global que é bastante aplicado 
utilizada no nosso trabalho. ${ }^{22}$

Na Tabela 4 mostramos comparamos as três elasticidades por setor, mas é importante lembrar que essa análise é questionável, uma vez que não há nenhuma razão a priori para assegurar que sejam iguais, uma vez que elas refletem características específicas da estrutura de consumo e de produção de cada país.

Inicialmente, verificamos que a média aritmética das elasticidades setoriais que obtivemos é 1,24 , representa apenas $44 \%$ de 2,8 calculadas para USITC e GTAP. Esse resultado indica que a substituição entre importações e produção domestica é mais difícil no Brasil — do que nos EUA ou do que em um país hipotético "convencional" - pois, para produzir uma mesma variação relativa do coeficiente de importação, a variação de preço relativo necessária é duas vezes maior. Isto é consistente com a percepção de que mesmo após a abertura comercial o Brasil ainda permanece relativamente fechada às importações. Outra possibilidade é que as elasticidades da USITC e do GTAP sejam altas demais e não representem, de fato, o comportamento das importações em um país com as nossas características.

Também é oportuno notar que a repercussão da diferença nas elasticidades apontada acima na curvatura da curva de indiferença não é tão significativa. Isto pode ser inferido da Figura 1, constatando que as curvas para $\sigma=1$ e $\sigma=3$, são bastante próximas entre si. $^{23}$

Como se depreende das estatísticas de amplitude e desvio padrão, na parte inferior da Tabela 4, as nossas estimativas apresentam uma variabilidade similar àquelas reportadas por Donnelly (2004). Chama a atenção, entretanto, o fato do valor mínimo ser surpreendentemente elevado (de 1,7 e 1,8, respectivamente, para USITC e GTAP), quando comparado ao valor nulo para o Brasil. Já quanto ao valor máximo da elasticidade, há também uma diferença numérica significativa (3,6 versus 5) que, no entanto, não representa uma distinção importante na curvatura da curva de indiferença, que é praticamente nula em ambos os casos, o que indica que nos setores onde a elasticidade é elevada, a substituição é quase perfeita, tanto no Brasil quanto nos países representados naqueles dois modelos.

Finalmente, é importante levar em conta que as diferenças entre as nossas estimativas e as mostradas em Donnelly (2004) podem estar relacionadas não apenas às características dos países, mas também à divergência nos procedimentos metodológicos. Os ajustes nas elasticidades estimadas baseados na opinião de especialistas setoriais (sistemática de Delphi) que aquelas instituições adotam podem levar à eliminação de valores extremos ou raros, induzida pela aversão ao risco de errar dos especialistas consultados.

Podemos concluir esta comparação internacional fazendo uma apreciação mais geral da Tabela 4, e notando que as diferenças são substantivas, e ocorrem muito mais freqüentemente que as coincidências. Isto é evidência eloqüente a desaconselhar o procedimento muitas vezes encontrado na literatura de fazer analises de impactos de política comercial e cambial adotando elasticidades calibradas a partir de valores observados para outros paises, supondo que as diferenças não sejam significativas. Pelo menos no período analisado este procedimento não é valido e pode resultar em avaliações equivocadas.

em exercícios de equilíbrio geral para avaliações dos impactos de acordos de comercio. As elasticidades extraídas dele são genéricas, que são adotadas quando elasticidades específicas não estão disponíveis para um determinado país. Elas derivam daquelas utilizadas no projeto SALTER da Australian Industry Commission Huff e alii (1997) e de outras informações coletadas na literatura econômica.

${ }^{22}$ Para todos os setores em que pudemos encontrar uma correspondência direta com setores de nosso estudo, transcrevemos os valores diretamente. Repetimos os valores daquele estudo para todos os setores de nossa classificação que puderam se considerados contidos na definição setorial adotada naquele estudo.

${ }^{23}$ A curva para elasticidade igual a 3 não foi representada na figura para preservar a sua clareza, mas sua posição pode ser depreendida do fato dela se situar entre as curvas para elasticidade 2 e 5 , mas muito mais próxima da primeira. 


\section{CONCLUSÕES}

Neste trabalho estimamos as elasticidades de substituição de Armington de 28 setores industriais da matriz de insumo-produto do Brasil, no período 1986-2002. Levamos em conta os efeitos da abertura comercial no inicio da década de 1990 e tomamos os cuidados necessários para respeitar as propriedades estatísticas das séries temporais envolvidas na estimação.

As elasticidades de Armington estimadas têm o sinal correto, sendo significativas a 5\% para 20 setores, a $10 \%$ para dois setores e a $20 \%$ para dois setores. Para um setor o valor estimado é significativo, porém tem o sinal negativo. Para três setores a elasticidade estimada não é significativamente diferente de zero, mas representam apenas $12 \%$ das importações no período 1997-2002. A estimativa pontual da elasticidade de substituição - positiva e estatisticamente não nula - varia de 0,16 a 3,6, atingindo a média de 0,93 quando ponderada pelas importações de cada setor.

Segundo a classificação adotada para a sensibilidade da elasticidade de substituição, temos dois setores com elasticidade muito alta $(\sigma \cong 3)$, oito com elasticidade alta $(\sigma \cong 2)$, nove com elasticidade média $(\sigma \cong 1)$, cinco com elasticidade baixa $(\sigma<0,5)$, três setores com elasticidade nula e um com elasticidade negativa. A média aritmética alcança 1,24 e a sua distribuição de freqüência é aproximadamente simétrica.

A comparação internacional mostra que, em média, as elasticidades setoriais que obtivemos é apenas $44 \%$ das elasticidades utilizadas nos modelos da USITC e do GTAP, mas a repercussão desta diferença na curvatura de curva de indiferença não é muito significativa. No entanto, a elasticidade mínima (entre os setores) naqueles modelos é surpreendentemente elevada, quando comparado ao valor nulo para o Brasil. Os valores máximos das elasticidades, apesar das diferenças numéricas, indicam uma substituição quase perfeita, tanto no Brasil quanto nos países representados naqueles dois modelos.

Por último, esperamos que as estimativas das elasticidades de Armington para o Brasil, por setor da matriz de insumo-produto, propiciem estimativas mais confiáveis e precisas dos impactos das mudanças na política comercial brasileira, tanto nos modelos de equilíbrio parcial quanto nos modelos de equilíbrio geral.

\section{Referências Bibliográficas}

Armington, P. S. (1969). A theory of demand for products distinguished by place of production. IMF Staff Papers, 16(1):159-177.

de Melo, J. \& Robinson, S. (1989). Product differentiation and the treatment of foreign trade in computable general equilibrium models of small economies. Journal of International Economics, 27(1-2):47-67. available at http://ideas.repec.org/a/eee/inecon/v27y1989i1-2p47-67.html.

Dervis, K., Melo, J. d., \& Robinson, S. (1982). General equilibrium models for development policy. Cambridge University Press.

Dickey, D. A. \& Fuller, W. A. (1981). Likelihood ratio statistics for autoregressive time series with a unit root. Econometrica, 49(4):1057-72. available at http://ideas.repec.org/a/ecm/emetrp/ v49y1981i4p1057-72.html.

Dolado, J. J., Jenkinson, T., \& Sosvilla-Rivero, S. (1990). Cointegration and unit roots. Journal of Economic Surveys, 4(3):249-73. available at http://ideas.repec.org/a/bla/jecsur/ v4y1990i3p249-73.html.

Donnelly, W. A. E. a. (2004). Revised armington elasticities of substitution for the usitc model and the concordance for constructing a consistent set for the gtap model. Office of Economics Research Note 2004-01-A, International Trade Commission, Washington, D.C. 
Enders, W. (1995). Applied econometric time series. John Wiley \& Sons.

FUNCEX (2002). Boletim setorial. Ano VI.

Gallaway, M. P., McDaniel, C. A., \& Rivera, S. A. (2003). Short-run and long-run industry-level estimates of u.s. armington elasticities. The North American Journal of Economics and Finance, 14(1):49-68. available at http://ideas.repec.org/a/eee/ecofin/v14y2003i1p49-68.html.

Hamilton, J. D. (1994). Time series analysis. Princeton University Press, Princeton, New Jersey.

Harrinson, G. W. \& alii (2003). Políticas comerciais regionais, multilaterais e unilaterais do mercosul para o crescimento econômico e redução da pobreza no brasil. Pesquisa e Planejamento Econômico, 33(1):1-60.

Hufbauer, G. \& Elliot, K. A. (1994). Measuring the costs of protection in the United States. Institute of International Economics, Washington, D.C.

Huff, K. M. \& alii (1997). Gtap behavioral parameters. In Global Trade Analysis: Modeling and Applications. Cambridge University Press.

Johansen, S. (1988). Statistical analysis of cointegration vectors. Journal of Economic Dynamics and Control, 12(2-3):231-254. available at http://ideas.repec.org/a/eee/dyncon/ v12y1988i2-3p231-254.html.

Kume, H. (1990). A política tarifária brasileira no período 1980-88: avaliação e reforma. Série ÉPICO 17, INPES/IPEA, Rio de Janeiro.

Madalla, G. S. \& Kim, I. M. (1998). Unit roots, cointegration, and structural change. Cambridge University Press.

Markwald, R. \& alli (1998). Índices de preço e quantum do comércio exterior. Texto para Discussão 134, Fundação Centro de Estudos de Comércio Exterior.

Perron, P. (1989). The great crash, the oil price shock, and the unit root hypothesis. Econometrica, 57(6):1361-1401. available at http://ideas.repec.org/a/ecm/emetrp/ v57y1989i6p1361-1401.html.

Sánchez, G. (2001). Beyond mercosur: costs and benefits of trade agreements with northern blocs. Technical report, Leral de la Fundación Mediterránea.

Tourinho, O., Kume, H., \& Pedroso, A. C. (2003). Elasticidades de armington para o brasil: 1986-2002. Texto para Discussão 974, IPEA.

\section{A. FONTE E TRATAMENTO DOS DADOS}

Os dados utilizados são trimestrais, desagregados por setor da matriz de insumo produto do IBGE (nível 50), no período 1986-2002.

Os índices de preço $\left(P_{i}^{m}\right)$ e de quantum das importações $\left(M_{i}\right)$ foram calculados pela Fundação Centro de Estudos do Comércio Exterior (Funcex), conforme metodologia descrita em Markwald e alli (1998), e estão disponíveis no IPEAData (www.ipea.gov.br). O índice de preço doméstico $\left(P_{i}^{d}\right)$ foi aproximado pelo Índice de Preço no Atacado (Oferta Global) da Fundação Getulio Vargas (IPA-OG-FGV), após a compatibilização entre os setores do IPA e os da matriz de insumo-produto, descrita na Tabela 5. Nos casos em que uma atividade da matriz de insumo produto corresponde a mais de um setor do IPA, o 
Tabela 5 - Compatibilização dos Setores da Matriz de Insumo-Produto e do IPA ${ }^{a}$

\begin{tabular}{ll}
\hline \multicolumn{1}{c}{ Setor da matriz de insumo-produto (nível 50) } & \multicolumn{1}{c}{ Setor do IPA-OG-FGV (coluna) } \\
\hline Extrativa mineral & Extrativa mineral (28) \\
Petróleo, gás natural, carvão e outros comb. & Combustíveis e lubrificantes (54) \\
Minerais não-metálicos & Calcários e silicatos (30) \\
Siderurgia & Ferro, aço e derivados (32) \\
Metalurgia dos não-ferrosos & Metais não-ferrosos (33) \\
Outros produtos metalúrgicos & Metalúrgica total (31) \\
Máquinas e tratores & Máquinas e equipamentos industri- \\
& ais (36) \\
Material elétrico & Material elétrico total (38) \\
Equipamentos eletrônicos & Material elétrico e outros (41) \\
Automóveis, caminhões e ônibus & Veículos a motor (43) \\
Outros veículos, peças e acessórios & Veículos a motor (43) \\
Madeira e mobiliário & Madeira (45), mobiliário total (46) \\
Papel e gráfica & Papel e papelão (50) \\
Indústria da borracha & Borracha (51) \\
Elementos químicos não-petroquímicos & Química e outros (58) \\
Refino do petróleo e indústria petroquímica & Química total (53) \\
Químicos diversos & Química total (53) \\
Farmacêuticos e perfumaria & Produtos farmacêuticos (81), perfu- \\
& maria, sabões e velas (82) \\
Material plástico & Matérias plásticas (56), produtos de \\
& matérias plásticas (83) \\
Indústria têxtil & Tecidos e fios naturais (60), tecidos e \\
& fios artificiais e sintéticos (61), ma- \\
Artigos do vestuário e acessórios & lharia (62) \\
Calçados, artigos de couro e peles & Vestuário (63) \\
Beneficiamento de produtos de origem vegetal, fumo & Calçados (64) \\
Abate e preparação de carnes & Carnes e pescado (78) \\
Leite e laticínios & Leite e derivados (79) \\
Óleos vegetais e gordura para alimentação & Óleos e gorduras (74) \\
Outros produtos alimentares e bebidas & Sal, rações e outros (80), bebidas \\
& (66) \\
Indústrias diversas & Indústria de transformação total \\
Abate e preparação de carnes & (29) \\
\hline a & Carnes e pescado (78) \\
\hline
\end{tabular}

\footnotetext{
${ }^{a}$ Fonte: IBGE e FGV. Elaboração própria.
} 
índice de preço foi calculado pela média simples, ou ponderada pelo valor da produção, quando este último estava disponível.

A taxa de câmbio utilizada $(X)$ corresponde à média mensal da cotação oficial de venda, publicada pelo Banco Central do Brasil.

O coeficiente de variação do preço relativo $\left(\frac{P_{i}^{d}}{P_{i}^{m}}\right)$ mede o efeito da incerteza, e foi calculado como a razão entre o desvio padrão e a média dessa variável em uma "janela" com seis meses de duração, centrada no mês mediano do trimestre para o qual o coeficiente está sendo calculado.

Para estimar o índice de quantum das vendas domésticas $\left(D_{i}\right)$ deflacionou-se o valor das vendas domésticas totais de cada setor $\left(V D T_{i}\right)$ pelo índice de preço doméstico respectivo $\left(P_{i}^{d}\right)$. O $V D T_{i}$ setorial foi calculado deduzindo o valor das exportações do valor da produção $\left(V P_{i}\right)$ correspondente que foi inferido a partir do seu valor na matriz insumo produto mais recente, e das variações dos índices de produção e preços setoriais entre o ano a que ela corresponde, e a data para a qual se está fazendo o calculo do valor da produção. Como a disponibilidade de dados é mais restrita antes de 1990, o procedimento sofreu pequena adaptação naquele caso, como se descreve a seguir.

Para o período 1986-1990, o valor das vendas domésticas totais $\left(V D T_{i}\right)$ foi estimado pela equação (28), que mostra que o valor referente a cada mês foi calculado aplicando as variações mensais observadas da quantidade e do preço sobre o valor médio das vendas totais de 1985 para, em seguida, deduzir o valor das exportações do respectivo mês. $O$ índice de quantum utilizado foi a produção industrial do IBGE por gênero ou por setor da matriz, depois de compatibilizar as classificações de setores e de gênero com o auxilio da Tabela 6 .

$$
V D T_{i t}=\left(\frac{V P_{i 85}}{12}\right) \cdot\left(\frac{q_{i t}}{q_{i 85}}\right) \cdot\left(\frac{P_{i t}}{P_{i 85}}\right)-V E_{i t}
$$

onde:

$V D T_{i t}=$ valor das vendas domésticas totais em reais do setor i no mês t;

$V P_{i 85}=$ valor da produção em reais a preço básico do setor i em 1985;

$q_{i t}=$ índice de produção física do setor i no mês t;

$q_{i 85}=$ índice de produção física do setor i, médio mensal em 1985;

$P_{i t}=$ índice de preço doméstico do setor i no mês t;

$P_{i 85}=$ índice de preço doméstico, do setor i, médio mensal em 1985;

$V E_{i t}=$ valor das exportações em reais do setor i no mês t.

A partir de 1991, foi adotado o mesmo procedimento descrito acima para o período anterior, com uma alteração: para cada mês de um determinado ano foi utilizado como base para aplicação das variações o valor das vendas totais médias no ano anterior, em vez do valor de 1985. Este procedimento alternativo permite um ganho de precisão, mas só foi possível porque nos períodos 1991-1996 e 19972002 o valor da produção doméstica é disponível anualmente na matriz de insumo produto e nas Contas Nacionais, respectivamente.

A tarifa nominal de cada setor $\left(\tau_{i t}\right)$, foi construída por um procedimento em três etapas. Inicialmente os produtos da classificação de comércio exterior segundo a Nomenclatura Brasileira de Mercadorias - Sistema Harmonizado (NBM-SH) e Nomenclatura Comum do Mercosul (NCM-SH) foram distribuídos pelos setores da matriz de insumo-produto (nível 80). Em seguida, para cada setor (nível 80) foi calculada a média aritmética simples das tarifas legais dos produtos inclusos nele, de acordo com aquela classificação. Finalmente, a tarifa nominal de cada atividade (nível 50) da matriz de insumo produto foi calculada como a média ponderada pelo valor de produção das tarifas dos setores (nível 80). 
A série de tarifas efetivas $\left(\bar{\tau}_{i t}\right)$ foi obtida calculando a razão entre a arrecadação do imposto de importação e o valor total das importações, por categoria de uso, segundo informações disponibilizadas pela Secretaria da Receita Federal do Ministério da Fazenda (SRF/MF) e, posteriormente, compatibilizado com a classificação setorial da matriz de insumo produto.

\section{B. DETERMINAÇÃO DA ORDEM DE INTEGRAÇÃO DAS SÉRIES}

Para determinar a ordem de integração das séries de preços e quantidades envolvidas na equação, empregamos a metodologia proposta por Enders (1995), complementada pelo teste de Perron (1989) para tratar a possibilidade de quebras estruturais.

Estimamos inicialmente a equação 29, que inclui uma tendência, uma constante, e componentes auto-regressivos, e testamos a existência de raiz unitária $(\gamma=0)$, utilizando a estatística $\mathrm{ADF}^{24}$ Caso aquela hipótese seja rejeitada, conclui-se que não existe raiz unitária e o procedimento é terminado.

$$
\Delta x_{t}=a_{0}+\gamma x_{t-1}+a_{2} t+\sum_{i=1}^{p} \beta_{i} \Delta x_{t-i}+\varepsilon_{t}
$$

Como este teste é caracterizado pela baixa potência, caso não rejeitemos a raiz unitária, testaremos a hipótese conjunta de existência daquela e ausência de tendência $\left(a_{2}=\gamma=0\right)$ utilizando a estatística $\phi_{3}$ de Dickey e Fuller (1981). Se rejeitarmos esta hipótese conjunta, testaremos novamente $\gamma=0$, utilizando a distribuição normal, e o procedimento é, então, finalizado. Se não conseguirmos rejeitar esta hipótese conjunta, supomos que o processo gerador dos dados pode ser expresso pela equação 30 e novamente realizamos o teste da raiz unitária com a estatística ADF.

$$
\Delta x_{t}=a_{0}+\gamma x_{t-1}+\sum_{i=1}^{p} \beta_{i} \Delta x_{t-i}+\varepsilon_{t}
$$

Se a hipótese nula de raiz unitária for rejeitada nesta especificação, o procedimento é finalizado. Caso não a rejeitemos, testaremos a hipótese nula de que $a_{0}=\gamma=0$, utilizando a estatística $\phi_{2}$ de Dickey e Fuller (1981). Se rejeitarmos esta hipótese conjunta, testaremos novamente $\gamma=0$, utilizando a distribuição normal e o procedimento é, então, finalizado. Não rejeitando a hipótese nula, testaremos a raiz unitária de acordo com a especificação da equação 31, utilizando a estatística ADF. Caso aceitemos (rejeitemos) $\gamma=0$, concluiremos que a série apresenta (não apresenta) raiz unitária.

$$
\Delta x_{t}=\gamma x_{t-1}+\sum_{i=1}^{p} \beta_{i} \Delta x_{t-i}+\varepsilon_{t}
$$

Em cada uma das equações acima, o número de defasagens utilizado (p) foi escolhido de acordo com o critério general to simple partindo de um número máximo igual a cinco. Se a quinta defasagem for significativa ao nível de $5 \%$, a mesma é mantida. Caso aquela não seja, a equação é estimada novamente, com quatro defasagens, sendo novamente verificado o nível de significância da última defasagem. O procedimento continua até que o coeficiente da última defasagem do componente autoregressivo seja significativo ao nível de $5 \%$.

É importante enfatizar que os resultados dos testes anteriormente descritos podem não ser conclusivos, caso haja quebra estrutural na série, já que as estatísticas ADF têm um viés favorável à não-rejeição da raiz unitária. Por isso, para as séries que apresentaram raiz unitária no procedimento anteriormente descrito aplicamos o teste de Perron (1989), admitindo que, segundo a tipologia lá proposta, a quebra estrutural fosse do tipo representado pelo changing growth model.

${ }^{24}$ Os valores críticos para as estatísticas ADF foram retirados de Hamilton (1994) para um nível de significância de $10 \%$. 


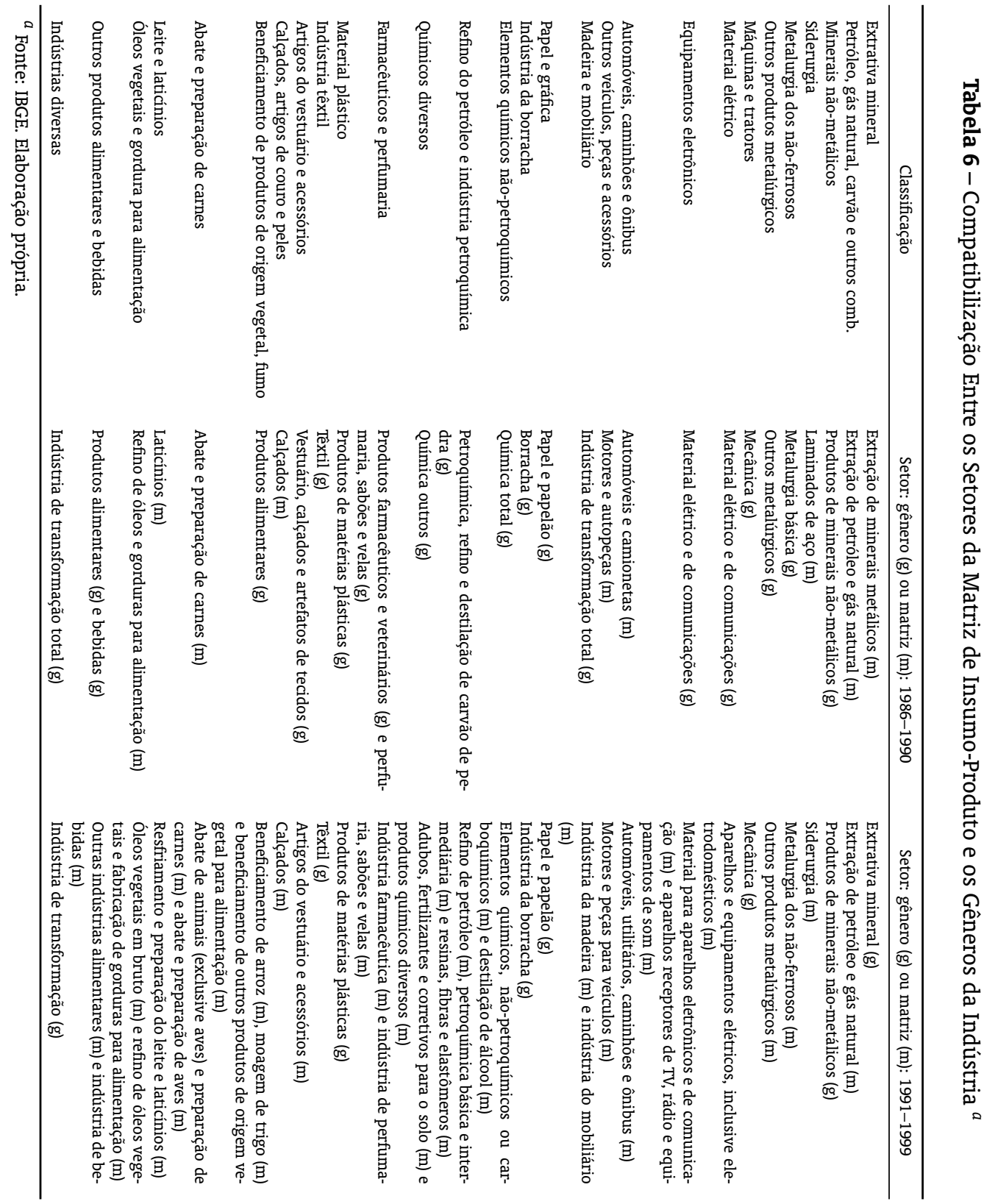


A equação 32 descreve este modelo, e foi construída de modo a acomodar tanto a hipótese nula quanto a hipótese alternativa do teste. Na hipótese nula supomos a existência de raiz unitária com mudança no intercepto do processo no instante de quebra estrutural. Na hipótese alternativa supõe-se que o processo seja estacionário com mudança na inclinação da linha de tendência determinística no momento da quebra.

$$
x_{t}=\mu+\theta U_{t}+\beta t+\gamma T_{t}+\alpha x_{t-1}+\sum_{i=1}^{p} \beta_{i} \Delta x_{t-i}+\varepsilon_{t}
$$

onde: $T_{B}=$ data da quebra estrutural; $U_{t}=1$, se $t>T_{B} t>T_{B} e U_{t}=0$, caso contrário; e $T_{t}=t-T_{B}$, se $\mathrm{t}>\mathrm{TB}$ e $T_{t}=0$, caso contrário.

A hipótese nula impõe as seguintes restrições nos parâmetros de (B.5):

$$
\alpha=1, \gamma=0, \beta=0 \text { e } \theta \neq 0
$$

A hipótese alternativa impõe as seguintes restrições nos parâmetros (B.6):

$$
\alpha<1, \gamma \neq 0, \beta \neq 0 \text { e } \theta=0
$$

A data considerada para a quebra das séries foi o quarto trimestre de 1990, e os valores críticos utilizados foram os de Perron (1989), com nível de significância de $10 \%$. O teste foi aplicado de modo seqüencial, adicionando componentes auto-regressivos até que a hipótese de auto correlação serial fosse rejeitada no teste de Ljung-Box, com nível de significância de 5\%. 